\title{
What Drives Healthcare Expenditure Growth? Evidence from Central and Eastern European Economies
}

\author{
Milena KONATAR* - Snježana KAŠTELAN** - Uršula KAŠTELAN*** _ \\ Jovan ĐURA ̌KOVIĆ* - Milivoje RADOVIĆ*
}

\begin{abstract}
The aim of this paper is to examine the determinants of healthcare expenditure in Central and Eastern Europe (CEE) countries. The study covers the period between the years 2000 and 2018. In our research, we implement error correction based on an autoregressive distributed lag (ARDL) model, with focus on the Pooled Mean Group (PMG) estimator. Our estimation results revealed that, in combination, health spending, income, medical progress, population ageing and fiscal capacity together form a statistically significant and stable long-term economic relationship. Our analysis indicates that healthcare spending responds to both short-term and long-term income changes. The obtained results support the prevailing view that health should not be considered a luxury good with an income elasticity close to unity. In the long term, medical progress and population ageing also significantly influence health spending, whilst these variables prove to be insignificant over the short term. Ultimately, government capacity is positively related to health spending dynamics.
\end{abstract}

Keywords: healthcare expenditures, CEE countries, panel ARDL modeling, income elasticity

JEL Classification: I10, O52, C33

DOI: https://doi.org/10.31577/ekoncas.2021.07.05

\footnotetext{
* Milena KONATAR - Jovan ĐURAŠKOVIĆ - Milivoje RADOVIĆ, The Faculty of Economics, University of Montenegro, 37 Bulevar Jovana Tomaševića, 81000 Podgorica, Montenegro; e-mail: milena.radonjic@live.com; jocodj@gmail.com; rmico@ac.me

** Snježana KAŠTELAN, School of Medicine, University of Zagreb, Šalata ul. 2, 10000 Zagreb, Croatia/Institute for Eye Diseases and Disorders, Clinical Hospital Dubrava, Avenija Gojka Šuška 6, 10000 Zagreb, Croatia; e-mail: snjezanakastelan@yahoo.com

*** Uršula KAŠTELAN, The Faculty of Economics and Business, University of Zagreb, Trg John F. Kennedy 6, 10000 Zagreb, Croatia; e-mail: ukastelan@ net.efzg.hr
} 


\section{Introduction}

Over the last four decades, demand for healthcare services worldwide has increased as a response to rising incomes. Wealthier nations tend to place greater value on quality of life and thus have a higher demand for medical services, causing an upsurge in healthcare spending. The rapid growth of healthcare expenditure has sparked debate regarding the possible drivers of its dynamics. Given that understanding the relationship between healthcare spending and its determinants is the key to designing effective healthcare policies, large bodies of work have focused on identifying the core drivers of health spending. In fact, researchers' have linked changes in healthcare expenditure to variables such as increasing income, advancements in medical technology, population ageing and changes in financing healthcare (Murthy and Ketenci, 2017; Murthy and Okunade, 2016; Ke, Saksena and Holly, 2011; Baltagi and Moscone, 2010; Dreger and Reimers, 2005; Cantarero and Lago-Peñas, 2010; Barkat, Sbia and Maouchi, 2019; Behera and Dash, 2018; Fan and Savedoff, 2014; Hartwig and Sturm, 2014). Although income is indisputably the most significant determinant of healthcare spending, a consensus regarding the intensity of its impact has not yet been reached. Thus, healthcare might, in certain contexts, be considered a luxury (Okunade, You and Koleyni, 2018; Musgrove, Zeramdini and Carrin, 2002; van der Gaag and Stimac, 2008), while in others it is viewed as a necessary good (Murthy and Ketenci, 2017; Murthy and Okunade, 2016; Baltagi and Moscone, 2010).

Over the last six decades, the pattern of healthcare expenditure has changed in Central and Eastern European (CEE) countries with small and open economies sharing a similar social and economic heritage, as well as a common experience of socio-economic transition and closely matched pre-accession phases in the process of joining the European Union (EU). The period of systems transitions in these countries entailed significant changes to their healthcare systems. During the period of communist rule, universal access to a wide range of health services was available. As it proved difficult to retain this coverage, many countries attempted to rationalize publicly funded health services through, for example, patient cost sharing or decreasing the scope of basic benefits (Kurpas, 2020). Despite their substantial social and economic progress during the last 30 years, CEE countries continue to lag behind their equivalents in Western Europe in terms of healthcare spending. Even though healthcare spending increased in absolute terms in all CEE countries between the years 2000 and 2018, on average they still spent significantly less on healthcare (5\% of GDP) than other countries in the EU (9.9\%).

As an example, the lowest share of healthcare expenditure was recorded in Romania (4\%) in 2000. Relative to population size, health expenditure per person 
in 2018 varied from 584 EUR in Bulgaria to 1,830 EUR in Slovenia, which is still considerably below the EU average (2,982 EUR). Since investing in healthcare generates wealth and population wellbeing, it is essential that countries from this region increase their health spending (Grossman, 1972). In particular, taking into account the fact that investing in health, as a form of capital, leads to an increase in labour productivity, followed by an increase in income and thus an increase in overall wellbeing, health is perceived as an important determinant of economic development. In that context, the core drivers of healthcare expenditure dynamics need to be investigated.

The main aim of this study is to examine the potential determinants of health spending dynamics in CEE countries. More specifically, we have posed two research questions: 1. What are the long and short-term relationships between healthcare expenditures and their drivers? and 2. Is health care a luxury or a necessary good in CEE countries?

In order to estimate the relationship between health spending and its core drivers, an autoregressive distributed lag model was applied, with a focus on the Pooled Mean Group (PMG) estimator. In addition, to the best of our knowledge, a similar study that deals with the same sample has as yet not been conducted, making this a particular contribution to the existing literature. Therefore, the aim of this paper is to fill this gap and provide insights into the determinants of healthcare expenditures in the $11 \mathrm{CEE}$ countries.

The study is structured as follows: After the introductory notes, we survey the most relevant empirical studies dealing with healthcare expenditure determinants worldwide. The subsequent sections included a description of our data and the methodological framework employed. The next section presents the empirical results and a discussion, where we compare our findings with previous empirical evidence. The final section forms the conclusion.

\section{Literature Review}

Research into the determinants of healthcare expenditure has a long history. Since the work by Newhouse (1977) numerous studies have attempted to identify the main drivers of healthcare expenditure. The role of real per-capita income, as the most important driver of health care expenditure, has been repeatedly confirmed in the literature.

A large and growing body of literature focuses on measuring the size of the income elasticity of healthcare, which determines whether healthcare is a luxurious or necessary good. A number of scientists argue that healthcare is a luxury good and as such should be left to market forces. In his pioneering work, 
Newhouse (1977) showed that $92 \%$ of health expenditure variations in 13 developed countries was explained by GDP and estimated income elasticity larger than one, implying that healthcare is a luxury good. Gertdham et al. (1992) obtained similar results for the 20 OECD countries and showed that income elasticity was also greater than one. In line with these results, the findings of some recent studies have shown that income elasticity ranged from 1.1 to 1.5 (Gerdtham and Jönsson, 2000; Musgrove, Zeramdini and Carrin, 2002; van der Gaag and Stimac, 2008; Okunade, You and Koleyni, 2018). On the other hand, a number of studies claim that healthcare is a necessary good, and thus government intervention is desirable in the healthcare sector. On a large sample of 143 countries, Ke, Saksena and Holly (2011) showed that income elasticity was highest in low-income countries, but still not greater than one, ranging from 0.75 to 0.95 in static models, while being much smaller in dynamic models. Using a panel of 20 OECD countries, Baltagi and Moscone (2010) showed that healthcare is a necessity, with income elasticity estimated at approximately 0.87 . Similarly, more recent studies conducted on data drawn from 50 US states showed that health care is income inelastic (Murthy and Ketenci, 2017; Murthy and Okunade, 2016).

Apart from income, the existing literature emphasizes the role of technological progress, as an important factor, which contributes to health expenditure dynamics. Various studies, conducted primarily on the basis of data from OECD countries, have used different proxies for medical progress such as surgical procedures and the number of pieces of specific medical equipment (Baker and Wheeler, 1998); the research and development spending that is specific to healthcare (Okunade and Murthy, 2002; You and Okunade, 2017); life expectancy and infant mortality (Dreger and Reimers, 2005) as well as international co-operation patents (Okunade, You and Koleyni, 2018). Using data from 23 OECD countries between 1960 and 2006, Smith, Newhouse and Freeland (2009) attributed as much as 26 percent of healthcare spending growth to technical change on its own and another 27 percent to the interaction between technical change and income. Irrespective of the proxy used, all the studies drew the same conclusion that medical progress is a significant driver of healthcare expenditure growth. Among non-income drivers of healthcare expenditures, the effects of ageing have been identified as an important source of healthcare variations. Due to the fact that an older population requires added healthcare services, it is expected that a larger share of the elderly in a particular population tends to increase healthcare costs (Barros, 1998; Okunade, Karakus and Okeke, 2004; Elk, Mot and Franses, 2009; Cantarero and Lago-Peñas, 2010; Barkat, Sbia and Maouchi, 2019). However, a number of studies have found that ageing effects are statistically insignificant (Di Matteo and Di Matteo, 1998; Gerdtham and Jönsson, 2000). 
Another determinant of health expenditure is fiscal capacity. The role of fiscal resources has been recognized as crucial in ensuring better access to healthcare services. Generally, with the increase of fiscal space, governments spend more on healthcare and other social sectors. This finding was confirmed by previous research, which established a positive relationship between the share of government expenditure in GDP and healthcare expenditure (Behera and Dash, 2018; Fan and Savedoff, 2014; Hartwig and Sturm, 2014; Hitiris, 1997; Ke, Saksena and Holly, 2011).

Various research has shown that health expenditures is most commonly driven by increasing income. Additionally, other factors such as population ageing, medical progress and government policy also contribute to health expenditure dynamics; however, there is no empirical consensus regarding their effects, which appear to depend on the methodology and the country or group of countries being analyzed. All of the above-mentioned studies refer to developed OECD countries or wider groups of lower income and developing countries, without reference to the CEE countries, making this study distinctive to a certain degree.

\section{Data and Methodology}

\subsection{Data}

This study used balanced panel data with 209 observations, covering the period between 2000 and 2018 for 11 CEE countries (Bulgaria, Croatia, the Czech Republic, Estonia, Hungary, Latvia, Lithuania, Poland, Romania, Slovakia and Slovenia).

The data was collected from two sources, the World Health Organization (National Health Accounts, NHA) and the World Development Indicators (WDI) of the World Bank. Health expenditure per capita (HE) included all expenditure on health services per capita expressed in 2018 purchasing power parity dollars to enable international comparison. We selected GDP per capita $(g d p)$ as the measure of income, also expressed in 2018 purchasing power parity dollars. Based on the literature, we expected a positive relationship between $H E$ and $g d p$. Both variables were selected from the NHA and transformed into their natural logarithmic forms in order to interpret the coefficients obtained by our regressions as elasticities.

Additionally, we included population ageing ( and the share of government expenditures in GDP $(g e)$, which were extracted from the WDI. We recorded medical progress with infant mortality (mor) per 1,000 live births, expressed in percentages. As a response to technological progress, we 
expected mor to be negative. The proportion of people over 65 years of age was selected to represent the effects of population ageing on healthcare expenditure, which was expected to be positive. Finally, government expenditure as a proportion of gross domestic product $(\mathrm{ge})$ measured the capacity of governments to mobilize revenues, which was also expected to be positive.

Table 1 summarizes the collected data and describes the features of the data used in the study. The mean, maximum, minimum and standard deviation (SD) estimations were performed in the descriptive analysis.

T a ble 1

Descriptive Statistics

\begin{tabular}{|l|c|c|c|c|c|}
\hline Variable & Observations & Mean & SD & Min & Max \\
\hline lnHe & 209 & 6.523 & 0.689 & 4.247 & 7.687 \\
Lngdp & 209 & 9.261 & 0.602 & 7.391 & 10.231 \\
Mor & 209 & 0.734 & 0.379 & 0.22 & 2.14 \\
Pop & 209 & 16.341 & 2.192 & 11.291 & 21.022 \\
Ge & 209 & 41.642 & 5.429 & 33.169 & 60.267 \\
\hline
\end{tabular}

Source: Authors' calculation.

The descriptive statistics showed a significant difference in both mean values and variability (measured by the standard deviation) between the variables. From this data, it is apparent that population ageing and government expenditures have higher means, but are also highly volatile.

\subsection{Methodology}

In order to explore the impact of the various determinants on healthcare expenditures in $11 \mathrm{CEE}$ countries, the research model was tested using a panel data framework. In the presence of non-stationary data, panel static approaches proved to be inappropriate, while the use of generalized method of moments (GMM) could lead to serious biases. Thus, this study used a panel autoregressive distributed lag model (ARDL) which simultaneously estimates both the shortand long-term dynamics. The ARDL model considered is an autoregressive model of the order $\mathrm{p}$ in the dependent variable, and an autoregressive model of the order $\mathrm{q}$ in the explanatory variables. The ARDL approach involves two steps for estimating a long-term relationship. The first step is to investigate the existence of a long-term relationship among all variables. If a long-term relationship between variables is confirmed, the second step is to estimate the long-term coefficients. According to them, cross-equation restrictions to the long-term parameters must be implemented by a maximum likelihood estimation in using this approach in panel data. 
In terms of the estimation methods, we employed dynamic heterogeneous panel data techniques, specifically the Pooled Mean Group (PMG) estimator and the Mean Group (MG) estimator. Since in this study the time dimension is greater than the cross-sectional dimensions $(\mathrm{T}=19 ; \mathrm{N}=11)$, dynamic mean group estimators were well suited to application in this situation. Both estimators, which were applied to estimate the non-stationary dynamic panels, considered the longterm equilibrium and the heterogeneity of the dynamic adjustment process. Since PMG and MG included the lags of both dependent and independent variables, the coefficients provided were consistent despite the possible presence of endogeneity.

The main difference between these two approaches is that MG relies on estimating $\mathrm{N}$ time-series regressions and averaging the coefficients, while the PMG estimator includes a combination of both the pooling and averaging of coefficients (Pesaran, Shin and Smith, 1999). Moreover, the MG estimator permits both the long-term and short-term slope parameters to vary between countries, while the PMG estimator permits only the short-term slope parameters to vary. The suitability of the two estimators can be tested by employing a standard Hausman-type statistic. In case of the validity of homogeneity restriction in the long-term, the PMG approach yields a more efficient estimate, as opposed to the MG estimator, which produces inefficient estimates. As such, in this study we uses the PMG estimator, on the basis that we expected the long-term relationships between variables to be similar across groups.

Following Pesaran, Shin and Smith (1999), we used a panel ARDL model for estimation purposes. The use of this model allows for the determination of both short-term and long-term coefficients, as well as error correction coefficients which indicate the long-term equilibrium speed. After establishing evidence of the existence of the cointegration between variables, the lag orders of the variables were chosen using the appropriate Akaike Information Criteria (AIC) or Schwarz Bayesian Criteria (SBC). The base model between healthcare expenditures and selected determinants as ARDL ( $\mathrm{p}, \mathrm{q} 1, \ldots, \mathrm{q} 4)$ is:

$$
\ln H E_{i, t}=\sum_{j=1}^{p} \lambda_{i j} \ln H E_{i, t-j}+\sum_{j=0}^{q} \delta_{i j}^{\prime} X_{i, t-j}+\mu_{i}+\varepsilon_{i, t}
$$

where $i=1,2, \ldots, 11$ stands for the country; $t=1,2, \ldots, 19$ for the time period; $\ln H E_{i t}$ for the dependent variable, which represents the natural logarithm of healthcare expenditure per capita; $X$ for the vector of explanatory variables (lngd $p_{i}$, which represents the natural logarithm of GDP per capita; pop $_{\text {it }}$ which represents the percentage of the population above 65 years of age; $g e_{i t}$ which represents total government expenditure as a share of GDP; and mor $_{i t}$ which represents the mortality rate as a proxy for medical progress); $\mu_{\mathrm{i}}$ standing for fixed effects and 
$\varepsilon_{i, t}$ as the disturbing component. For modeling purposes, health expenditure and income were converted into their natural logarithmic forms, since all the remaining variables were expressed in percentages (Cantarero and Lago-Peñas, 2010).

Equation (1) can be reparametrized as an error-correction (EC) form:

$$
\Delta \ln H E_{i, t}=\phi_{i}\left(\ln H E_{i, t-1}-\theta_{i}^{\prime} X_{i, t}\right)+\sum_{j=1}^{p-1} \lambda_{i j}^{*} \Delta \ln H E_{i, t-1}+\sum_{j=0}^{q-1} \delta_{i j}^{* *} \Delta X_{i, t-1}+\mu_{i}+\varepsilon_{i . t}
$$

The parameter $\phi_{i}=-\left(1-\sum_{j=1}^{p} \lambda_{i j}\right)$ represents the error-correcting speed of adjustment term, which estimates the speed of adjustment of health expenditure toward its long-term equilibrium following a change in any of its determinants. In the case of the existence of a long-term relationship, the value of parameter $\phi_{i}$ was significantly negative and can be regarded as evidence of cointegration between health expenditures and selected variables. The parameters $\lambda_{i j}^{*}$ and $\delta_{i j}^{\prime *}$ represent the individual short-term coefficients of the lagged dependent and independent variables respectively, while the vector $\theta_{i}^{\prime}$ captures the long-term relationships between the variables.

The estimation procedure followed in this study consisted of five stages. Initially, we conducted a cross-sectional dependence test (CD), as proposed by Pesaran (2004). Upon confirming the presence of cross-section dependence, in the following stage we used second-generation panel unit root tests, specifically a crosssectionally augmented Dickey-Fuller (CADF) and a cross-sectionally augmented Im-Pesaran-Shin (CIPS) panel unit root test (Pesaran, 2007). In the third stage, we checked the cointegrated relationship among variables using the Westerlund (2007) cointegration test. In the fourth, after affirming the cointegration, we employed the PMG estimator to determine the short and long-term impact of the selected variables on healthcare expenditure. In the final stage, we conducted a Dumitrescu-Hurlin panel causality test in order to investigate the direction of the causality between health spending and its determinants.

\section{Empirical Results and Discussion}

The first stage of our empirical analysis requires the confirmation of the presence or absence of cross-sectional dependence in the variables, in order to determine whether to use first- or second-generation econometric techniques in the successive analysis (Pesaran, 2004). If cross sectional dependence exists in the panel data, first-generation techniques may provide misleading results. Thus, second-generation techniques are appropriate in case of cross-sectional dependence. 
The results of the Pesaran test for cross-sectional dependence are presented in Table 2. The results indicated that for all the variables, the null hypothesis of cross-section independence could be rejected at a $1 \%$ level of significance, indicating the existence of cross-sectional dependence in the variables.

Table 2

Pesaran Test for Cross-sectional Dependence

\begin{tabular}{|l|c|c|}
\hline & CD test & p-value \\
\hline lnHE & $31.118^{* * *}$ & 0.000 \\
Lngdp & $31.638^{* * *}$ & 0.000 \\
Pop & $31.217 * * *$ & 0.000 \\
ge & $7.898^{* * *}$ & 0.000 \\
Mor & $31.499 * * *$ & 0.000 \\
\hline
\end{tabular}

Notes: *** Indicates the rejection of the null hypothesis of cross-sectional independence (CD test) at a $1 \%$ significance level.

Source: Authors' calculation.

Following the results of the cross-sectional dependence test, in the second stage of our analysis we used second-generation unit root tests, specifically a crosssectionally augmented Dickey-Fuller (CADF) test and a cross-sectionally augmented Im-Pesaran-Shin (CIPS) panel unit root test (Pesaran, 2007). Although testing for the order of integration of variables is not important for the application of the ARDL model as long as the variables of interest are $\mathrm{I}(0)$ and $\mathrm{I}(1)$, we nonetheless conducted these tests in order to ensure that no series exceeded the I(1) order of integration. The results of the CIPS and CADF test are shown in Table 3, both for levels and for first differences. All the variables, except for the variable pop are integrated in the order of 1 (I(1)).

T a ble 3

Panel Unit Root Tests - CIPS and CADF

\begin{tabular}{|l|l|l|l|l|}
\hline Variable & \multicolumn{2}{|c|}{ CIPS } & \multicolumn{2}{c|}{ CADF } \\
\hline & Level & Difference & Level & Difference \\
\hline lnHE & $\mathbf{- 1 . 7 1 3}$ & $\mathbf{- 3 . 5 9 9 * * *}$ & $\mathbf{- 1 . 7 3 4}$ & $\mathbf{- 2 . 8 1 4} * * *$ \\
lngdp & -1.986 & $-2.892 * * *$ & -2.370 & $-2.849 * * *$ \\
pop & $-3.125 * * *$ & $-4.481 * * *$ & $-2.458 * * *$ & $-2.946 * * *$ \\
ge & -2.075 & $-4.275 * * *$ & -1.800 & $-2.908 * * *$ \\
mor & -1.485 & $-3.112 * * *$ & -1.765 & $1.858 * * *$ \\
\hline
\end{tabular}

Notes: *** Indicates that the test statistic is significant at the $1 \%$ level.

Source: Authors' calculation.

After verifying the order of integration, we proceeded with the panel cointegration test. The results of the Westerlund (2007) test are shown in Table 4. This test provides consistent evidence of long-term relationships among variables by rejecting the null hypothesis (no cointegration) at the $1 \%$ level. 
Ta ble 4

\section{Westerlund Cointegration Test}

\begin{tabular}{|l|c|c|c|}
\hline Statistics & Value & z-value & p-value \\
\hline $\mathrm{G}_{\mathrm{t}}$ & $-3.121 * * *$ & -4.571 & 0.000 \\
$\mathrm{G}_{\mathrm{a}}$ & $-10.982^{* *}$ & -1.684 & 0.046 \\
$\mathrm{P}_{\mathrm{t}}$ & $-8.910^{* * *}$ & -3.466 & 0.000 \\
$\mathrm{P}_{\mathrm{a}}$ & $-10.267 * * *$ & -3.149 & 0.001 \\
\hline
\end{tabular}

Notes: $* * *$ and $* *$ indicate statistical significance at the levels of $1 \%$ and $5 \%$, respectively.

Source: Authors' calculation.

After the cointegration of the variables was verified, we applied a panel autoregressive distributed lag ARDL $(1,1,1,1,1)$ model, with a focus on the PMG model. The lag was imposed according to the data limitations and confirmed by the Akaike Information Criteria (AIC) and the Schwarz Bayesian Criteria (SBC). The estimations of the long-term and short-term impacts of the selected variables on health expenditures are given in Table 5 .

Table 5

Panel Short- and Long-term Coefficients: Pooled Mean Group Estimator

\begin{tabular}{|l|c|c|}
\hline Variable & & \\
\hline & Long-term estimates & Short-term estimates \\
\hline Lngdp & $0.915^{* * *}$ & \\
& $(0.019)$ & \\
\hline Pop & $0.425^{* *}$ & \\
\hline Ge & $0.192)$ & \\
& $(0.065)$ & $-0.559^{* * * *}$ \\
\hline Mor & $-0.294^{* * *}$ & $(0.079)$ \\
\hline ECT(-1) & $(0.035)$ & $0.912^{* * *}$ \\
& & $(0.032)$ \\
\hline$\Delta$ lngdp & & 1.470 \\
& & $(0.982)$ \\
\hline A pop & & $0.228^{* *}$ \\
& & $(0.093)$ \\
\hline g ge & & -0.209 \\
& & $(0.302)$ \\
\hline$\Delta$ mor & & $-0.655^{* * *}$ \\
& & $(0.089)$ \\
\hline Constant & & 198 \\
\hline Observations (N) & & 402.884 \\
\hline Log likelihood & & $\chi^{2} \mathbf{( 4 )}=\mathbf{3 . 6 3}[0.459]$ \\
\hline Hausman specification test: & & \\
\hline
\end{tabular}

Notes: $* * *$ and $* *$ indicate significance at the levels of $1 \%$ and $5 \%$, respectively. The value in parenthesis represents the standard error. For the Hausman test, the $p$-values are reported in parenthesis.

Source: Authors' calculation. 
As can be seen, the error-correction coefficient estimates were statistically significant and negative, implying the tendency of the variables to converge towards the long-term relationship. The value of this coefficient $(-0.559)$ indicated that any deviation from the long-term equilibrium is corrected by approximately $55.9 \%$ in one period.

Furthermore, a Hausman test was conducted to check the validity of the restrictions. The results of the Hausman test indicated that the restriction of homogeneity in the long term could not be rejected at the $1 \%$ significance level. Thus, the PMG estimation is appropriate for the investigation of healthcare expenditure determinants in CEE countries.

The estimation results demonstrated that the income elasticity is positive and statistically significant both in the long and the short term. The study confirms the argument that, as a country's income increases, it tends to spend more on population healthcare, which supports the findings of Nghiem and Connelly (2017) and Zhou et al. (2020). Income elasticity was estimated to be less than unity, suggesting that healthcare should be regarded as a necessity in CEE countries. This finding is consistent with other studies, such as those conducted by Baltagi and Moscone (2010) and Ke, Saksena and Holly (2011).

Furthermore, population ageing contributes to higher healthcare spending over the long term. An increase in the share of the population aged over 65 by one percent is associated with an increase in total healthcare expenditure by 0.425 percent. The obtained results point to the fact that having an elderly population increases healthcare costs, due to this necessitating more complex health maintenance and treatment procedures (Okunade, You and Koleyni, 2018). However, in the short term, this variable was not deemed significant, implying that changes related to population aging require more time to show a significant effect (Murthy and Ketenci, 2017).

According to the estimations, infant mortality, as a proxy for advances in medical technology, is negatively related to healthcare spending in the long term (Dreger and Reimers, 2005). Technological advancement, expressed through a decrease in infant mortality, represents a major driving force behind healthcare expenditure growth, which is a finding supported by other studies including those by Zhou et al. (2020) and Okunade, You and Koleyni (2018). This suggests that the use of sophisticated procedures and medical treatment can be very expensive, but that such investments are necessary to raise the quality of the healthcare services in CEE countries. As was the case with the aging population variable, advances in medical technology were not significant in the short term, suggesting the need for longer follow-up periods for these improvements to show an effect. 
Finally, the government's capacity to mobilize revenues proved to be an important driver of healthcare spending, in both the short and the long term. To be specific, a one-percentage point increase in the share of government expenditures as a proportion of GDP was associated with a 0.237 or 0.228 percent increase in total healthcare expenditures in the long and short term, respectively. This finding that greater governmental fiscal capacity leads to higher healthcare spending is consistent with the results of other comparable studies (Ke, Saksena and Holly, 2011; Fan and Savedoff, 2014).

In the final stage of our study, we conducted a pairwise Dumitrescu and Hurlin causality test in order to check the direction of causality between the variables. The objective of this test is to verify both the direct and reverse causalities between healthcare spending and the explanatory variables. The null hypothesis of this test states that an independent variable does not homogeneously cause the dependent variable. Table 6 presents the results of the pairwise Dumitrescu-Hurlin causality test for different combinations of independent and dependent variables.

Ta b l e 6

\section{Dumitrescu-Hurlin Panel Causality Test}

\begin{tabular}{|l|c|}
\hline Null Hypothesis: & Zbar-stat. \\
\hline $\ln H E$ does not homogeneously cause $\ln G D P$ & $1.206^{* * *}$ \\
$\ln G D P$ does not homogeneously cause $\ln H E$ & $0.913^{* * *}$ \\
$\ln H E$ does not homogeneously cause $p o p$ & $0.073^{* *}$ \\
pop does not homogeneously cause $\ln H E$ & $0.52^{* * *}$ \\
$\ln H E$ does not homogeneously cause $g e$ & $5.011^{* * *}$ \\
ge does not homogeneously cause $\ln H E$ & $5.255^{* * *}$ \\
$\ln H E$ does not homogeneously cause $m o r$ & $-1.885^{* *}$ \\
mor does not homogeneously cause $\ln H E$ & $-1.75^{* *}$ \\
\hline
\end{tabular}

Notes: $* * *$ and $* *$ indicate significance at the levels of $1 \%$ and $5 \%$, respectively.

Source: Authors' calculation.

According to the results, there is bidirectional causality between health spending and the determinants included in the model. However, the relationship between health spending and economic growth is especially important in the context of policy implication. To be clear, higher levels of economic development imply higher levels of health spending. At the same time, higher health spending might also translate to economic growth through the higher quality of available human capital, which represents a consequence of increased health expenditure.

\section{Conclusion}

This paper provides an empirical analysis of the determinants of healthcare expenditure in CEE countries. For that purpose, we used error correction based on the ARDL $(1,1,1,1,1)$ model, with a focus on the PMG estimator. 
We found that healthcare spending, income, medical progress, population ageing and fiscal capacity together form a statistically significant and stable longterm economic relationship. Being consistent with most recent findings in the literature, our analysis indicates that healthcare spending responds to both long and short-term income change, with an income elasticity close to unity. In the long-term, health spending is also significantly influenced by medical progress and population ageing, while these variables proved to be insignificant in the short-term. Additionally, government spending capacity was positively related to healthcare spending dynamics, implying that fiscal resources are important in ensuring better access to essential healthcare services in the CEE region.

The results obtained have important policy implications. Generally, with a higher level of economic development, there is a tendency towards increase demand for a higher level of health services, leading to an upsurge in healthcare spending. One obvious policy conclusion is that CEE countries should allocate a greater proportion of their national spending to healthcare, since investment in healthcare creates wealth. Even though there is growing concern regarding the rapid rise in healthcare expenditure, such developments allow access to new technologies as well as medical treatments and procedures, having real health benefits and improving quality of life. It is therefore necessary to implement measures that stimulate healthcare productivity which converts into slower growth in healthcare spending or increased health benefits. The adoption of more efficient medical technologies and the improvement of healthcare financing mechanisms may prove to be appropriate measures aimed at achieving real health benefits. Additionally, the use of private budgets to cover medical expenses, a well-known feature of healthcare systems in Central and Eastern European countries, is primarily implemented in healthcare policies, and is aimed at reducing the burden of patient health problems. The economic determinants of healthcare become particularly evident in times of financial crisis, having a significant impact on the planning of healthcare expenditure and the healthcare system itself. In times of recession, it is crucially important to protect underprivileged and vulnerable groups (Kaštelan et al., 2020; Kaštelan et al., 2020a). Currently, out-of-pocket payments constitute a major source of healthcare financing, with patients being confronted with a range of payment obligations for the use of healthcare services. Thus, policy makers should provide financial protection against out-of-pocket payments, primarily for the most vulnerable population groups, in order to achieve fundamental health policy goals, most notably equality and accessibility.

Ultimately, our study has shown that increasing income leads to higher healthcare spending while on the other hand, health spending stimulates economic growth, which is closely related to the endogenous growth theory. However, it is 
necessary to mention that this topic has become especially important in the current COVID-19 pandemic. The COVID-19 pandemic triggered not only a health crisis but a global economic crisis as well. The pandemic suppression policies which were introduced to save lives, also led to deep economic contraction worldwide. Despite the sharp decline in government revenues, health spending increased as the pandemic required an immediate response in order to save lives, which led to an increase in public debt as governments were forced to borrow to finance their deficits. This was not the case during other economic crises, when health spending had the same movement pattern as economic activity, i.e. health spending declined with the general slowdown of economic activity. Thus, it is very difficult to estimate with a great degree of certainty how long it will take for global economy to recover and how the situation will develop in the future. According to the projections made by the International Monetary Fund, it will take GDP per capita until 2023 to reach pre-COVID-19 levels globally (Kurowski et al., 2021) while health spending will have to be maintained at a high level in order to control the pandemic and create the preconditions for economic recovery.

However, the long-term repercussions of the pandemic in terms of changing the functioning of health systems and priorities in national economies are still difficult to envisage (Kaštelan et al., 2020). Even so, this crisis could serve as a reminder that investing in the health sector is very important. Having said that, it is worth repeating that it is not only about the quantity of health spending, but also the quality: with care, investing in health should improve the equity and efficiency of health systems worldwide, which will protect them from threats to their sustainability.

\section{References}

BAKER, L. C. - WHEELER, S. K. (1998): Managed Care and Technology Diffusion: The Case of MRI. Health Affairs, 17, No. 5, pp. 195 - 207. Available at: <http://dx.doi.org/10.1377/hlthaff.17.5.195>.

BALTAGI, B. H. - MOSCONE, F. (2010): Health Care Expenditure and Income in the OECD Reconsidered: Evidence from Panel Data. Economic Modelling, 27, No. 4, pp. $804-811$. Available at: <http://dx.doi.org/10.1016/j.econmod.2009.12.001>.

BARKAT, K. - SBIA, R. - MAOUCHI, Y. (2019): Empirical Evidence on the Long and Short Run Determinants of Health Expenditure in the Arab World. The Quarterly Review of Economics and Finance, 73, No. C, pp. 78 - 87. Available at: <https://doi.org/10.1016/j.qref.2018.11.009>.

BARROS, P. P. (1998): The Black-box of Health Care Expenditure Growth Determinants. Health Economics, 7, No. 6, pp. 533 - 544. Available at: <https://doi.org/10.1002/(SICI)1099-1050(199809)7:6<533::AID-HEC374>3.0.CO;2-B>.

BEHERA, D. K. - DASH, U. (2018): Healthcare Financing in South-East Asia: Does Fiscal Capacity Matter? International Journal of Healthcare Management, 13, No. 4, pp. 1 - 10. Available at: <https://doi.org/10.1080/20479700.2018.1548159>. 
CANTARERO, D. - LAGO-PEÑAS, S. (2010): The Determinants of Health Care Expenditure: A Reexamination. Applied Economics Letters, 17, No. 7, pp. 723 - 726. Available at: <https://doi.org/10.180/1350485082314437>.

DI MATTEO, L. - DI MATTEO, R. (1998): Evidence on the Determinants of Canadian Provincial Government Health Expenditures, 1965 - 1991. Journal of Health Economics, 17, No. 2, pp. 211 - 228. Available at: 〈http://dx.doi.org/10.1016/S0167-6296(97)00020-9>.

DREGER, C. - REIMERS, H. E. (2005): Health Care Expenditures in OECD Countries: A Panel Unit Root and Cointegration Analysis. International Journal of Applied Econometrics and Quantitative Studies, 2, No. 2, pp. 5 - 20. Available at: <http://ideas.repec.org/p/iza/izadps/dp1469.html>.

ELK, R. - MOT, E. - FRANSES, P. H. (2009): Modelling Health Care Expenditures; Overview of the Literature and Evidence from a Panel Time Series Model. [CPB Discussion Paper, No. 121.] Hague: CPB Netherlands Bureau for Economic Policy Analysis. Available at: <https://www.cpb.nl/sites/default/files/publicaties/download/modelling-health-careexpenditures-overview-literature-and-evidence-panel-time-series-mod.pdf $>$.

FAN, V. Y. - SAVEDOFF, W. D. (2014): The Health Financing Transition: A Conceptual Framework and Empirical Evidence. Social Science and Medicine, 105, pp. 112 - 121. Available at: 〈http://dx.doi.org/10.1016/j.socscimed.2014.01.014〉.

GERDTHAM, U. G. - JÖNSSON, B. (2000): International Comparisons of Health Expenditure: Theory, Data and Econometric Analysis. In: CULYER, A. J. and NEWHOUSE, J. P. (eds): Handbook of Health Economics, 1, pp. 11 - 53. Amsterdam: Elsevier. Available at: <http://dx.doi.org/10.1016/S1574-0064(00)80160-2>.

GROSSMAN, M. (1972): On the Concept of Health Capital and the Demand for Health. The Journal of Political Economy, 80, No. 2, pp. 223 - 255. Available at: $<$ http://www.jstor.org/stable/1830580>.

HARTWIG, J. - STURM, J. E. (2014): Robust Determinants of Health Care Expenditure Growth. Applied Economics, 46, No. 36, pp. 4455 - 4474. Available at: <http://dx.doi.org/10.1080/00036846.2014.964829>.

HITIRIS, T. (1997): Health Care Expenditure and Integration in the Countries of the European Union. Applied Economics, 29, No. 1, pp. 1 - 6. Available at: <https://doi.org/10.1080/000368497327335>.

KAŠTELAN, S. - KASUN, B. - KAŠTELAN, U. - RADONJIĆ, M. - SOPTA, M. (2020): Economic Crises as a Motive for Change in Healthcare Systems - A Historical Perspective. Acta Medico-historica Adriatica, 18, No. 2, pp. 355 - 374. Available at: $<$ https://doi.org/10.31952/amha.18.2.8>.

KAŠTELAN, S. - SOPTA, M. - RADONJIĆ, M. - KAŠTELAN, U. (2020a): Financial Crisis and the Impact on the Health System. In: TOTH, I. (ed.): 13th International Scientific and Professional Conference Crisis Management Days 2020 Proceedings, Velika Gorica, Croatia. Velika Gorica: University of Applied Science Velika Gorica, pp. 430 - 438.

KE, X. - SAKSENA, P. - HOLLY, A. (2011): The Determinants of Health Expenditure: A Countrylevel Panel Data Analysis. [WHO Working Paper, No. 26.] Geneva: World Health Organization. Available at: <https://r4d.org/wpcontent/uploads/TransisitionsInHealthFinancing_Determinantsof Expenditures.pdf>.

KUROWSKI, C. - EVANS, D. - EOZENOU, P. - SCHMIDT, M. - IRWIN, A. - CAIN, J. PAMBUDI, E. - POSTOLOVSKA, I. (2021): From Double Shock to Double Recovery: Implications and Options for Health Financing in the Time of COVID-19. [The World Bank Group Discussion Paper, March 2021.] Washington, DC: The World Bank Group. Available at: <https://doi.org/10.1596/35298>.

KURPAS, D. (2020): Challenges in Implementing Integrated Care in Central and Eastern Europe Experience of Poland. International Journal of Integrated Care, 20, No. 2, pp. 1 - 6. Available at: <http://doi.org/10.5334/ijic.5533>. 
MURTHY, V. N. R. - KETENCI, N. (2017): Is Technology Still a Major Driver of Health Expenditure in the United States? Evidence from Cointegration Analysis with Multiple Structural Breaks. International Journal of Health Economics and Management, 17, No. 1, pp. 29 - 50. Available at: <http://dx.doi.org/10.1007/s10754-016-9196-2>.

MURTHY, V. N. R. - OKUNADE, A. A. (2016): Determinants of U.S. Health Expenditure: Evidence from Autoregressive Distributed Lag (ARDL) Approach to Cointegration. Economic Modelling, 59, No. C, pp. 67 - 73. Available at: 〈http://dx.doi.org/10.1016/j.econmod.2016.07.001〉.

MUSGROVE, P. - ZERAMDINI, R. - CARRIN, G. (2002): Basic Patterns in National Health Expenditure. Bulletin of the World Health Organization, 80, No. 2, pp. 134 - 146. Available at: <https://apps.who.int/iris/handle/10665/71118>.

NEWHOUSE, J. P. (1977): Medical-care Expenditure: A Cross-national Survey. The Journal of Human Resources, 12, No. 1, pp. 115 - 125. Available at: 〈http://dx.doi.org/10.2307/145602〉.

NGHIEM, S. H. - CONNELLY, L. B. (2017): Convergence and Determinants of Health Expenditures in OECD Countries. Health Economics Review, 7, No. 1, pp. 1 - 11. Available at: <http://dx.doi.org/10.1186/s13561-017-0164-4>.

OKUNADE, A. A. - MURTHY, V. N. R. (2002): Technology as a "Major Driver" of Healthcare Costs: A Cointegration Analysis of the Newhouse Conjecture. Journal of Health Economics, 21, No. 1, pp. 147 - 159. Available at: 〈http://dx.doi.org/10.1016/S0167-6296(01)00122-9>.

OKUNADE, A. A. - KARAKUS, M. C. - OKEKE, C. (2004): Determinants of Health Expenditure Growth of the OECD Countries: Jackknife Resampling Planestimates. Health Care Management Science, 7, No. 3, pp. 173 - 183. Available at: <http://dx.doi.org/10.1023/B:HCMS.0000039380.42784.20>.

OKUNADE, A. A. - YOU, X. - KOLEYNI, K. (2018): Cross-country Medical Expenditure Modeling Using OECD Panel Data and ARDL Approach: Investigating GDP, Technology and Aging Effects. In: BALTAGI, B. and MOSCONI, F. (eds): Contributions to Economic Analysis, 294, pp. 327 358. Bingley: Emerald. Available at: <http://dx.doi.org/10.1108/S0573-855520180000294018>.

PESARAN, M. (2007): A Simple Panel Unit Root Test in the Presence of Cross-section Dependence. Journal of Applied Econometrics, 22, No. 2, pp. 265 - 312. Available at: <https://doi.org/10.1002/jae.951>.

PESARAN, M. H. (2004): General Diagnostic Tests for Cross Section Dependence in Panels. [Cambridge Working Papers in Economics, No. 0435.] Cambridge: Faculty of Economics, University of Cambridge. Available at: <http://www.econ.cam.ac.uk/research-files/repec/cam/pdf/cwpe0435.pdf>.

PESARAN, M. - SHIN, Y. - SMITH, R. (1999): Pooled Mean Group Estimation of Dynamic Heterogeneous Panels. Journal of the American Statistical Association, 94, No. 446, pp. 621 - 634. Available at: <https://doi.org/10.2307/2670182>.

SMITH, S. - NEWHOUSE, J. P. - FREELAND, M. S. (2009): Income, Insurance, and Technology: Why Does Health Spending Outpace Economic Growth? Health Affairs, 28, No. 5, pp. 1276 1284. Available at: 〈http://dx.doi.org/10.1377/hlthaff.28.5.1276>.

VAN DER GAAG, A. - STIMAC, J. V. (2008): Towards a New Paradigm for Health Sector Development. [Technical Partner Paper, No. 3.] New York: The Rockefeller Foundation. Available at: <https://healthmarketinnovations.org/sites/default/files/Toward\%20a\%20New\%20Paradigm\% 20for\%20Health\%20Sector\%20Development.pdf>.

WESTERLUND, J. (2007): Testing for Error Correction in Panel Data. Oxford Bulletin of Economics and Statistics, 69, No. 6, pp. 709 - 748. Available at: <https://doi.org/10.1111/j.1468-0084.2007.00477.x>.

YOU, X. - OKUNADE, A. A. (2017): Income and Technology as Drivers of Australian Healthcare Expenditures. Health Economics, 26, No. 7, pp. 853 - 862. Available at: $<$ http://dx.doi.org/10.1002/hec >.

ZHOU, L. - AMPON-WIREKO, S. - ANTWI, H. A. - XU, X. - SALMAN, M. - ANTWI, M. AFUA, T. M. (2020): An Empirical Study on the Determinants of Health Care Expenses in Emerging Economies. BMC Health Services Research, 20, No. 774, pp. 1 - 16. Available at: <https://doi.org/10.1186/s12913-020-05414-Z>. 